\title{
The tribological behavior of some steel samples prepared by powder metallurgy sintered in microwave field
}

\author{
Adrian OLEI ${ }^{1, a^{*}}$, Sorin SAVU ${ }^{1, b}$ and Iulian STEFAN ${ }^{1, c}$ \\ ${ }^{1}$ University of Craiova, Faculty of Mechanics, Department of Engineering and Management of \\ Technological Systems, No.1, Calugareni street, 220037, Drobeta Turnu Severin, Romania \\ aadrian_olei@yahoo.com, borin.savu@yahoo.com, 'stefan_iuly@yahoo.com
}

Keywords: microwave sintering, powder metallurgy, wear testing

\begin{abstract}
The objective of this research is to study the influence of the sample composition on the wear testing for some steel samples elaborated by powder metallurgy technology. For obtaining the steels there were used iron powders and graphite powders. The powders were homogenized in a high energy ball mill Pulverisette 6, cold compacted and then sintered using a Muegge type microwave heating installation. The influence of the samples' composition on the wear parameters is studied using both a tribometer and a profilometer.
\end{abstract}

\section{Introduction}

Nowadays, the requirement for friction systems that operate in hard conditions are growing constantly [1]. Steels, considered to be the most important material in engineering, are widely used and applied, but in atmosphere conditions it oxidates [2,3]. Thus, powders addition are used in order to obtain better tribological properties in steels [4,5]. So, recent research proved that high wear resistance was obtained in steels, by incorporating powders additions, together with the improvement of hardness [6,7]

The objective of the current research is to study the influence of the sintering technique on the tribological behavior of the samples prepared through the powder metallurgy (P.M.) route.

\section{Materials and experimental procedure}

The samples were prepared using a P.M. specific route, the two starting materials used in the research were iron and graphite powders and the ratios between them were the following: $99,5 \%$ iron $/ 0,5 \%$ graphite; $99 \%$ iron $/ 1 \%$ graphite and $98,5 \%$ iron $/ 1,5 \%$ graphite.

The powders were homogenized in a high energy ball mill, cold compacted and sintered using a Muegge type microwave heating installation (figure 1).

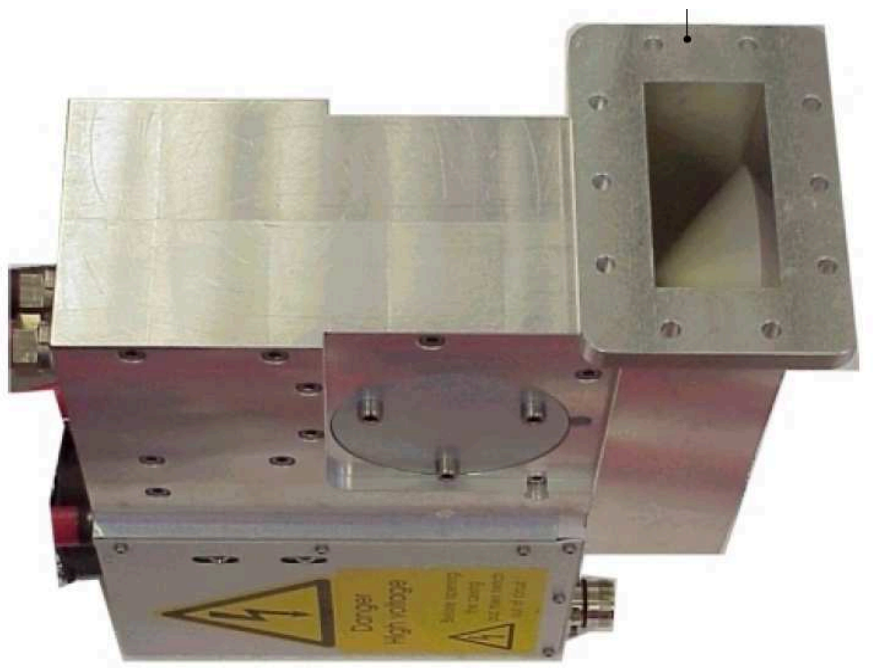

Fig. 1. The microwave heating installation 
The microwave sintering parameters are presented in table below (tabel 1).

Table 1. The microwave sintering parameters

\begin{tabular}{|c|c|c|c|}
\hline Sample & $\begin{array}{c}\text { Compacting pressure, } \\
{[\mathrm{MPa}]}\end{array}$ & $\begin{array}{c}\text { Temperature, } \\
{\left[{ }^{\circ} \mathrm{C}\right]}\end{array}$ & $\begin{array}{c}\text { Maintaining time, } \\
\text { [sec] }\end{array}$ \\
\hline $99,5 \% \mathrm{Fe} / 0,5 \% \mathrm{C}$ & \multirow[t]{3}{*}{ (2: } & \multirow{3}{*}{1100} & \multirow{3}{*}{120} \\
\hline $99 \% \mathrm{Fe} / 1 \% \mathrm{C}$ & & & \\
\hline $98,5 \% \mathrm{Fe} / 1,5 \% \mathrm{C}$ & & & \\
\hline
\end{tabular}

After that the samples were wear tested using a pin-on-disk tribometer from CSM Instruments in order to determine the evolution of the friction coefficient in time. Also, with a Surtronic 25 profilometer there were determined the worn track depth, the worn track surface and the wear rates of the samples.

\section{Results and Discussions}

The results of the wear testing performed on the samples prepared to the P.M. itinerary are presented in table 2 .

Table 2. Parameters of the worn track profiles of the samples

\begin{tabular}{|c|c|c|c|c|}
\hline Sample & $\begin{array}{c}\text { Friction } \\
\text { coefficient }[\boldsymbol{\mu}]\end{array}$ & $\begin{array}{c}\text { Worn track } \\
\text { depth }[\boldsymbol{\mu m}]\end{array}$ & $\begin{array}{c}\text { Worn track } \\
\text { surface }\left[\boldsymbol{\mu m}^{\mathbf{2}}\right]\end{array}$ & $\begin{array}{c}\text { Wear rate } \\
{\left[\mathbf{m m}^{\mathbf{3}} / \mathbf{N m}\right]}\end{array}$ \\
\hline $99,5 \% \mathrm{Fe} / 0,5 \% \mathrm{C}$ & 0,556 & 3,21 & 459 & $1,101 \cdot 10^{-4}$ \\
\hline $99 \% \mathrm{Fe} / 1 \% \mathrm{C}$ & 0,444 & 3,44 & 182 & $4,365 \cdot 10^{-5}$ \\
\hline $98,5 \% \mathrm{Fe} / 1,5 \% \mathrm{C}$ & 0,394 & 3,03 & 125 & $2,998 \cdot 10^{-5}$ \\
\hline
\end{tabular}

By the worn track depth point of view, the smallest value $(3,03 \mu \mathrm{m})$ is obtained for the sample $98,5 \% \mathrm{Fe} / 1,5 \% \mathrm{C}$, while the biggest value $(3,44 \mu \mathrm{m})$ is obtained for the sample $99,5 \% \mathrm{Fe} / 0,5 \% \mathrm{C}$. More, the smaller worn track surface $\left(125 \mu^{2}\right)$ was obtained for the sample $98,5 \% \mathrm{Fe} / 1,5 \% \mathrm{C}$, while the biggest worn track surface $\left(459 \mu^{2}\right)$ was obtained for the sample $99,5 \% \mathrm{Fe} / 0,5 \% \mathrm{C}$.

Regarding the wear rate obtained for each sample, the best value was obtained for the sample $98,5 \% \mathrm{Fe} / 1,5 \% \mathrm{C}$, while the worst value is obtained for the sample $99,5 \% \mathrm{Fe} / 0,5 \% \mathrm{C}$.

In figure 2 there are presented the evolution of the friction coefficient (figure $2 \mathrm{a}$ ) and the profile of the worn track (figure $2 \mathrm{~b}$ ) for the sample $98,5 \% \mathrm{Fe} / 1,5 \% \mathrm{C}$.

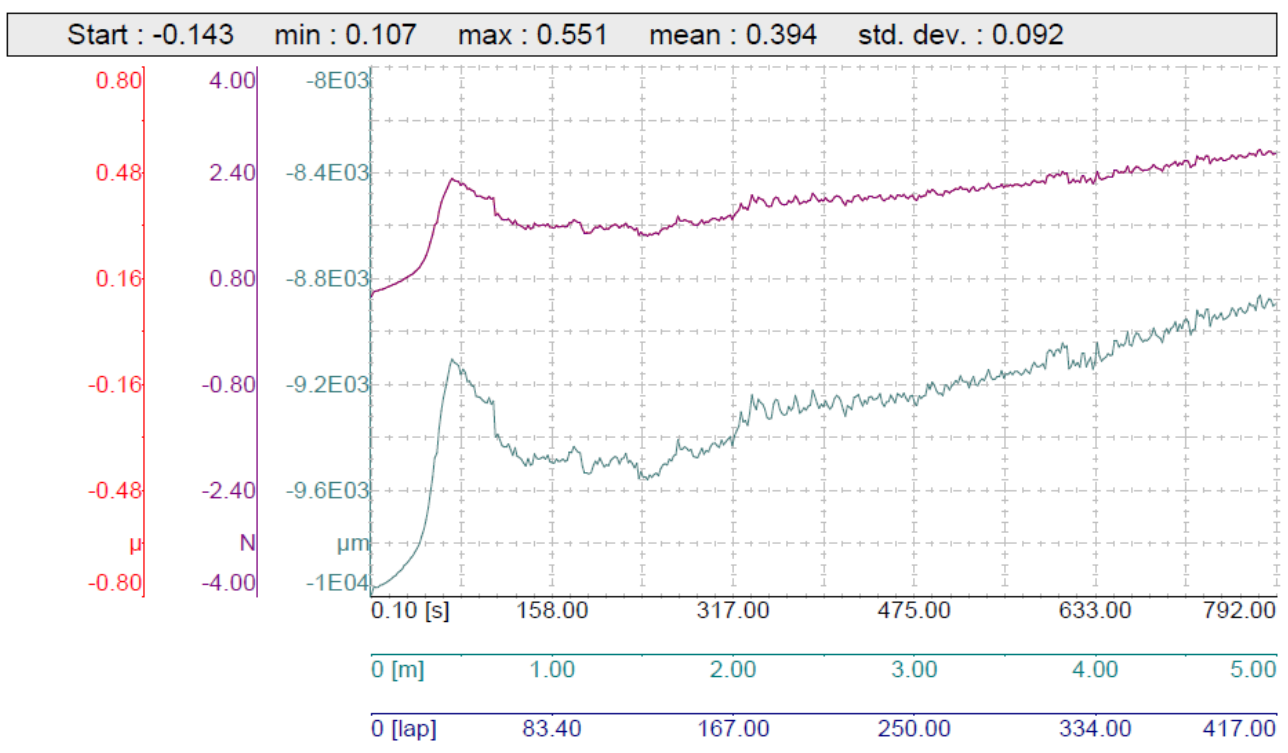

a. 


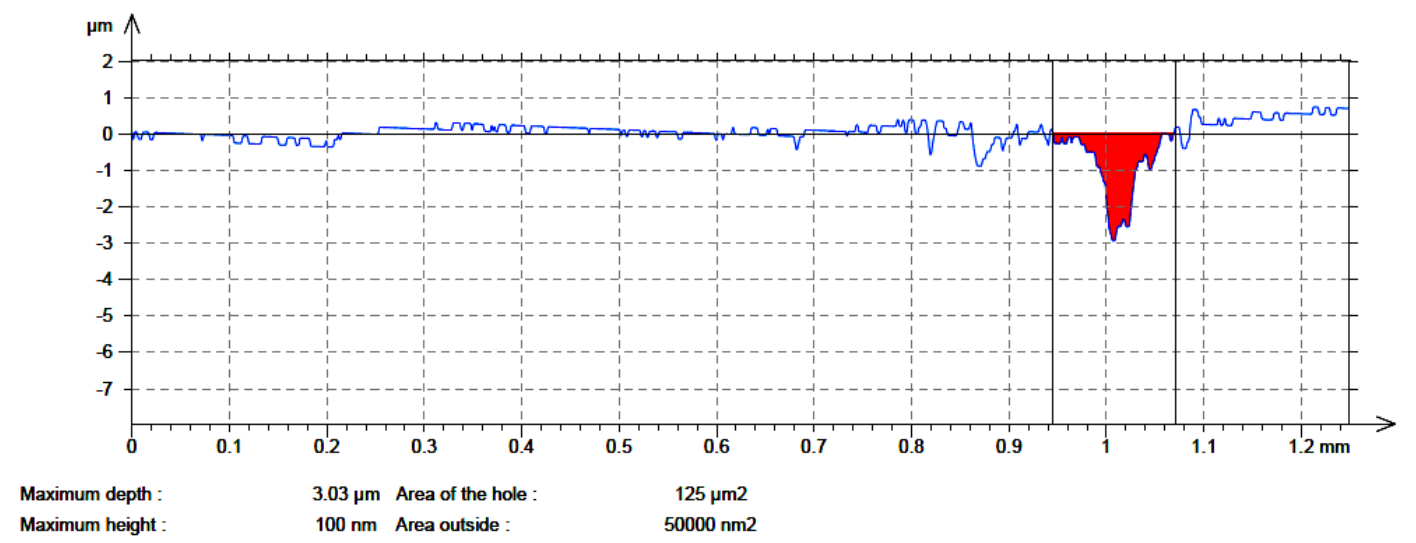

b.

Fig. 2. Wear testing results for the sample $98,5 \% \mathrm{Fe} / 1,5 \% \mathrm{C}$ :

a. evolution of the friction coefficient; $b$. profile of the worn track

In figure 3 there are presented the evolution of the friction coefficient (figure $3 \mathrm{a}$ ) and the profile of the worn track (figure $3 \mathrm{~b}$ ) for the sample $99,5 \% \mathrm{Fe} / 0,5 \% \mathrm{C}$.

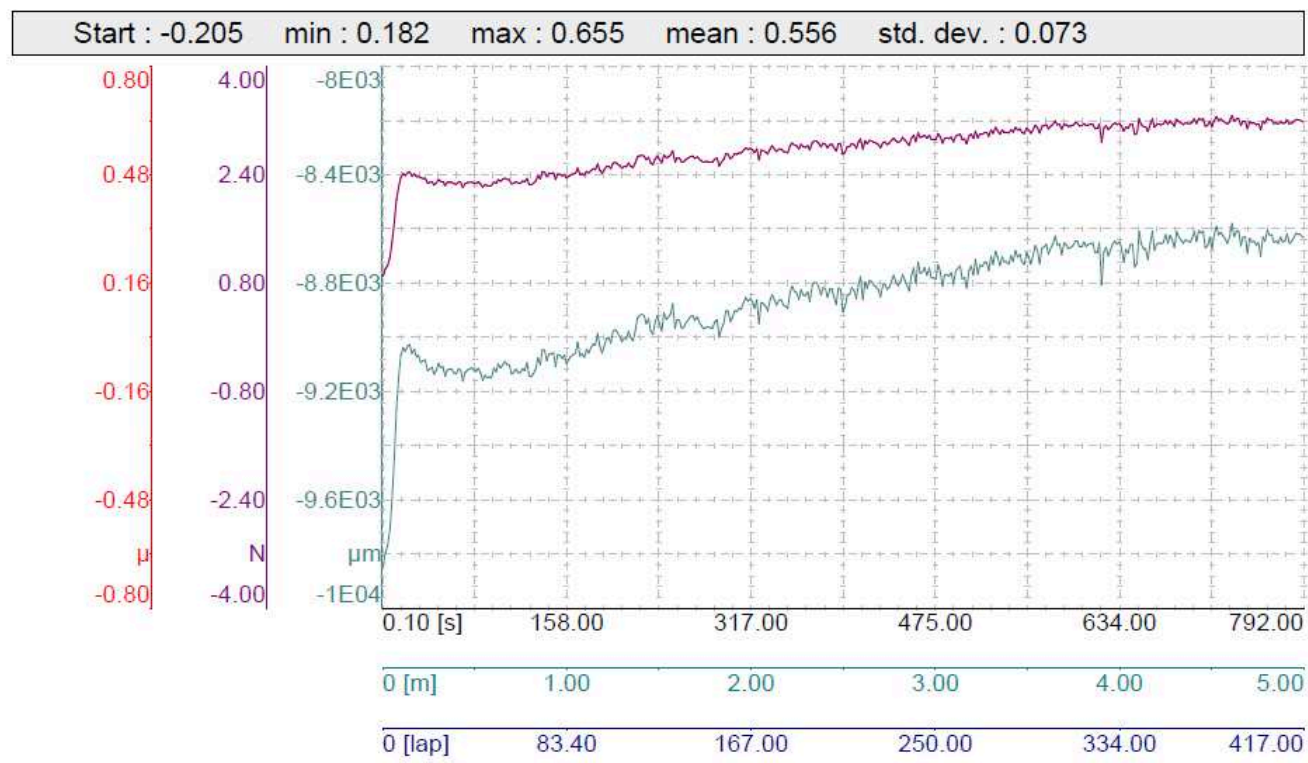

a.

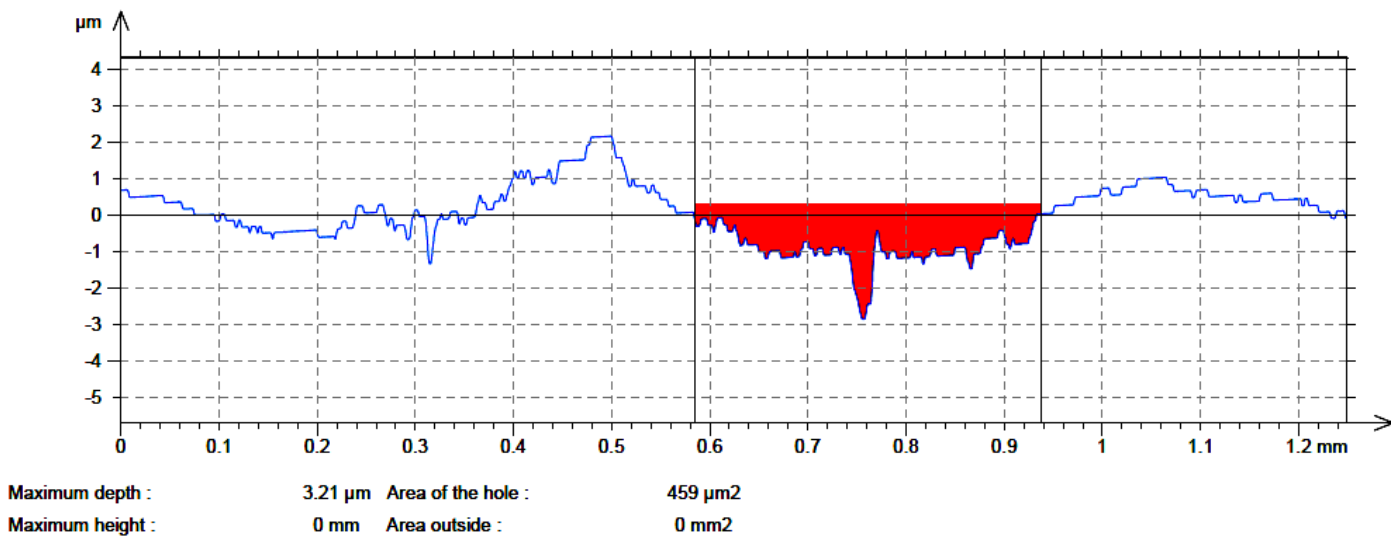

b.

Fig. 3. Wear testing results for the sample $99,5 \% \mathrm{Fe} / 0,5 \% \mathrm{C}$ :

a. evolution of the friction coefficient; b. profile of the worn track

Until the temperature of $500^{\circ} \mathrm{C}$, the temperature evolution is constant, with a $10^{\circ} \mathrm{C} /$ minute heating gradient. After the $500^{\circ} \mathrm{C}$ temperature, due to the transformations from the structure of the 
nacelle material, it became powerful microwave absorbing, which led to the increase of the heating gradient with $5^{\circ} \mathrm{C} /$ minute, thus becoming $15^{\circ} \mathrm{C} /$ minute.

\section{Conclusions}

The steels prepared through a P.M. specific route showed a good wear behaviour, being obtained good wear parameters.

The sintering in microwave field technique provided the main advantage of the short sintering time (120 seconds), compared to the classic sintering technique.

The general assessment of the wear behaviour of the steel samples is that the sintering in microwave field technology delivers the advantage of the good wear behaviour of the processed materials, with no debris pulled out of the worn surface.

Overall, the best wear parameters were obtained for the sample $98,5 \% \mathrm{Fe} / 1,5 \% \mathrm{C}$, while the worst wear parameters were obtained for the sample $99,5 \% \mathrm{Fe} / 0,5 \% \mathrm{C}$.

\section{References}

[1] S.Q. Wang et al., Mild-to-severe wear transition and transition region of oxidative wear in steels, Wear 306 (2012) 311-320.

[2] S.Q. Wang, M.X. Wei, Y.T. Zhao, Effects of the tribo-oxide and matrix on dry sliding wear characteristics and mechanisms of a cast steel, Wear 269 (2010) 424-434.

[3] O. Barrau, C. Boher, R. Gras, F. Rezai-Aria, Analysis of the friction and wear behavior of hot work tool steel for forging, Wear 255 (2003) 1444-1454.

[4] G.A. Fontalvo, C. Mitterer, The effect of oxide-forming alloying elements on the high temperature wear of a hot work steel, Wear 258 (2005) 1491-1499.

[5] C. Edgar, Bain, Functions of the Alloying Elements in Steel, American Society of Materials, Ohio, 1939.

[6] C. Chattopadhyay, S. Sangal, K. Mondal, A. Garg, Improved wear resistance of medium carbon microalloyed bainitic steels, Wear 289 (2012) 168-179.

[7] Olei A., Stefan I., Popescu N., The influence of the sintering temperature on the wear testing for some steels samples obtained by powder metallurgy, Solid State Phenomena 216 (2014) 216-221. 